\title{
Impact of asphyxia on red blood cell folate concentration levels in newborns
}

\author{
Revakova $\mathrm{T}^{1}$, Vasilenkova $\mathrm{A}^{2}$, Ujhazy $\mathrm{E}^{3}$, Dubovicky $\mathrm{M}^{3}$, Mach $\mathrm{M}^{3}$, Brucknerova $\mathrm{I}^{4}$ \\ 1st Department of Paediatrics, Medical Faculty, Comenius University in Bratislava and University \\ Children's Hospital, Bratislava, Slovakia. zikavska@gmail.com
}

\section{ABSTRACT}

OBJECTIVES: To determine whether red blood cell (RBC) folate concentration levels are correlated with the occurrence of neonatal asphyxia and to study the effects of gestational age, gender, and mode of delivery on RBC folate concentration levels in newborns.

BACKGROUND: Asphyxia is one of the frequent causes of morbidity and mortality of newborns. Severe perinatal asphyxia can arise due to many factors.

METHODS: In a prospective study, the RBC folate concentrations were determined on day 1 of life in the whole group $(n=181)$ of full-term $(n=121)$ and preterm $(n=60)$ newborns. Immunochemical analysis for the determination of folate in erythrocytes was performed.

RESULTS: RBC folate concentration levels in asphyxiated newborns $(n=16)$ were significantly decreased (median $974 \mathrm{ng} / \mathrm{ml} ; \mathrm{p}=0.023$ ) in comparison with healthy newborns. On the other hand, the RBC folate concentration levels were significantly increased in preterm newborns (median $1,212 \mathrm{ng} / \mathrm{ml} ; \mathrm{p}=0.01$ ) in comparison with full-term newborns (median 1,098 $\mathrm{ng} / \mathrm{ml}$ ). Higher RBC folate concentration levels were found in newborns which had been delivered by Caesarean section (median 1,188 $\mathrm{ng} / \mathrm{ml} ; \mathrm{p}=0.02$ ) compared to those born vaginally (median 1,098 ng/ml).

CONCLUSION: Our results confirmed a significant decrease in RBC folate concentration in asphyxiated newborns on their first day of life (Fig. 4, Ref. 36). Text in PDF www.elis.sk.

KEY WORDS: asphyxia, preterm newborn, full-term newborn, delivery, red blood cell folate.

Abbreviations: RBC - red blood cell, EDTA - ethylenediaminetetraacetic acid, MTHFR - methylenetetrahydrofolate reductase

\section{Introduction}

Asphyxia is one of the most frequent causes of morbidity and mortality in neonates. Severe perinatal asphyxia can arise due to many factors on the side of both the mother and the newborn.

Perinatal asphyxia is still a health concern worldwide. It can result from many factors. Maternal malnutrition can also increase the risk of perinatal asphyxia and is a major cause of neurologic

${ }^{1} 1$ st Department of Paediatrics, Medical Faculty, Comenius University
in Bratislava and University Children's Hospital, Bratislava, Slovakia,
${ }^{2}$ Department of Clinical Biochemistry, University Children's Hospital,
Bratislava, Slovakia, ${ }^{3}$ Institute of Experimental Pharmacology and Toxi-
cology, Slovak Academy of Sciences, Bratislava, Slovakia, ${ }^{4}$ Department
of Neonatology and Intensive Medicine. Faculty of Medicine, Comenius
University, Bratislava, Slovakia

Address for correspondence: T. Revakova, MD, PhD, Limbova 1, SK83340 Bratislava, Slovakia.

Phone: +421.911148447

Acknowledgements: This work was supported by grants (GUK 320/2011, 376/2012) and by the Ministry of Education, VEGA 2/0081/11. The laboratory work was performed in cooperation with the Department of Clinical Biochemistry in Children's University Hospital, Slovak Republic. We are grateful to the 1st Department of Gynaecology and Obstetrics, Slovak Medical University and University Hospital in Bratislava. damage (1). If persistent, perinatal asphyxia is a condition of impaired blood gas exchange that leads to progressive hypoxemia and hypercapnia with metabolic acidosis (2). Perinatal asphyxia interferes with neonatal development and results in long-term deficits associated with mental and neurological diseases with delayed clinical onset (3) including severe mental retardation, spastic quadriplegia, microcephaly, seizures, and sensory impairment. The degree of abnormality determined upon neonatal examination, electroencephalogram, and neuroimaging studies predicts the neurodevelopmental outcome (2).

Higher prevalence of perinatal asphyxia was documented in male sex and in African-American race (4). Perinatal asphyxia occurs in up to $25 \%$ of infants of diabetic mothers. It may result from prematurity, Caesarean delivery, intrauterine hypoxia caused by maternal vascular disease, or macrosomia (2).

During perinatal asphyxia, the primary insult relates to the duration of the period of lacked oxygenation and leads to death if not re-established. Re-oxygenation leads to a secondary insult related to a cascade of biochemical events required for restoring proper function (3). Strong hypoxia might lead to the apoptosis induction (5).

There is no specific blood test to diagnose perinatal asphyxia. Some of biochemical indices are metabolic acidosis with $\mathrm{pH}<$ 7.0 and base excess $<20 \mathrm{mEq} / \mathrm{L}(2)$. Some authors applied heart markers as early indicators and prognostic parameters of perinatal asphyxia (6). Also some markers of oxidative stress can be decreased during perinatal asphyxia. The increase in total anti- 
417-421

oxidant capacity in asphyxiated term newborns could take place based on certain ability of asphyxiated term newborns to prevent the damage of balance between overproduction of malondialdehyde and antioxidants (7). Malondialdehyde is one of the oxidative stress indicators in human body. After folate supplementation, a significant malondialdehyde decrease was observed in colostrum and mature human milk (8). In combination with clinical signs of asphyxia and other biochemical blood parameters it is possible to predict severity of the asphyxial insult (9).

Folate-mediated one-carbon metabolism is essential for metabolic processes in the body (10). Interference of abnormal metabolism in the pathogenesis of neurological and vascular diseases has been published (11). The importance of folates and other nutrients during critical stages of pregnancy is currently recognized. The exposure to epigenetic changes is responsible for altering the mechanisms of growth and metabolism and leads to changes that may persist throughout life causing an increased susceptibility to disease. Some factors before and after birth can decrease levels of stress (12). Risk factors associated with birth defects of central nervous system include deficiency in folate supplementation, cigarette smoking, and exposure to x-rays (13). In developing countries, folic acid and iron supplementation of pregnant women could be beneficial to prevent children's malnutrition. Folic acid participates in cardiovascular prevention (14).

Adequate nutrition which was recorded in the reduction in hyperhomocysteinemia is an important factor in prevention of cardiovascular diseases (15). The risk of stable ischemic heart disease increases due to hyperhomocysteinemia. Slovak patients with stable ischemic heart disease were found to yield high prevalence of hyperhomocysteinemia (16).

The study is aimed at determining whether red blood cell (RBC) folate concentration levels are correlated with the occurrence of neonatal asphyxia and at studying the effects of gender on RBC folate concentration levels in newborns.

\section{Materials and methods}

The study comprised newborns $(n=181)$ hospitalized at the Department of Neonatology in Children's University Hospital in Bratislava between 2010 and 2012. Blood samples from umbilical cord were collected on their first day of life. Full-term newborns (group $\mathrm{A}$ : $\mathrm{n}=121$; sub-group $\mathrm{A}_{1:}$ healthy: $\mathrm{n}=117$; sub-group $\mathrm{A}_{2}$ : asphyxiated: $n=4$; gestational age 38 to 41 ; median of birth weight $3450 \pm 750$ grams) and preterm newborns (group B: $n=60$; subgroup $B_{1:}$ healthy: $n=48$; sub-group $B_{2}$ : asphyxiated: $n=12$ gestational age 27 to 37 ; median of birth weight $1600 \pm 850$ grams) were included in this study. All newborns with hemolytic disease of the newborn, multiple congenital anomalies, and severe bleeding with blood losses over $2 \mathrm{~g} / \mathrm{dl} / 24$ hours were excluded. Perinatal asphyxia was defined by metabolic or mixed acidemia $(\mathrm{pH}<7.00)$ in umbilical cord arterial blood sample, persistence of Apgar score below 4 points in 5th minute of life, and presence of neurological symptoms (2).

Blood samples for determining RBC folate were collected in vacutainers containing EDTA and taken to the Department of Clinical Biochemistry in Hospital for Children in Bratislava. Within 24 hours of collection, full blood count analysis (especially hematocrit) was undertaken. Remaining blood was stored at $-20^{\circ} \mathrm{C}$ for up to one month according to specifications of the producer sets and consistent with literature data (17). The blood samples were defrosted and processed within one month. The lysing agent ( $1.5 \mathrm{ml} 0.2 \%$ ascorbic acid) was added to $50 \mu 1$ of whole blood for RBC folate analysis (Roche Diagnostics, Germany). Immunochemical analysis was performed with the use of chemiluminescent emission (analyser cobas e 411). It was based on a competitive test using natural folate binding protein specific for folate. Folate competes with added folate for the binding sites of folate binding protein labeled with ruthenium complex.

Statistical analyses were based on frequency analysis calculated at $97 \%$ accuracy with confidence limits for proportion. Analysis of median values for $\mathrm{RBC}$ folate concentration levels was done by Mann-Whitney or Kruskal-Wallis tests. The relationship between both groups of asphyxiated and non-asphyxiated newborns was assessed by Kendall rank correlation coefficient. The same analyses were performed in comparison with gender (male, female), gestational age (preterm, full-term newborns) and mode of delivery (spontaneous, Caesarean delivery). Differences were regarded as statistically significant at $\mathrm{p}<0.05$. Analyses were performed by statsdirect version 2.8.0.

The study was approved by the Ethics Committee of University Hospital in Bratislava and the Ethics Committee of Children's University Hospital in Bratislava. Informed consent was obtained from every enrolled newborn's mother.

\section{Results}

RBC folate concentration levels in asphyxiated newborns (n $=16$ ) were significantly decreased (median $974 \mathrm{ng} / \mathrm{ml} ; \mathrm{p}=0.023$ ) (Fig. 1) in comparison with healthy newborns. Based on the low number of patients in each sub-groups $\left(\mathrm{A}_{1}, \mathrm{~A}_{2}, \mathrm{~B}_{1}, \mathrm{~B}_{2}\right)$, we did not analyze these results statistically.

The decreased RBC folate concentration levels are not associated with gender (male:female / 1:1.15) (Fig. 2). The median of red blood cell folate concentration of males was $1,167 \mathrm{ng} / \mathrm{ml}$ and that of females $1.127 \mathrm{ng} / \mathrm{ml}(\mathrm{p}=0.67)$.

On the other hand, the RBC folate concentration levels were significantly increased in preterm newborns (median $1,212 \mathrm{ng} / \mathrm{ml}$; $\mathrm{p}=0.01$ ) (Fig. 3) in comparison with full-term newborns (median $1,098 \mathrm{ng} / \mathrm{ml}$ ). In the group of asphyxiated newborns, $75 \%$ were identified as preterm newborns.

The other impact on RBC folate concentration levels was the mode of delivery. The study group comprised newborns born by Caesarean section due to complications on the maternal or newborn's side or due to placental abnormalities. Higher RBC folate concentration levels were found in newborns which were born by Caesarean section (median $1188 \mathrm{ng} / \mathrm{ml} ; \mathrm{p}=0.02$ ) (Fig. 4) compared to those born vaginally (median $1098 \mathrm{ng} / \mathrm{ml}$ ).

\section{Discussion}

According to the American Academy of Pediatrics and the American College of Obstetricians and Gynecologists, perinatal as- 


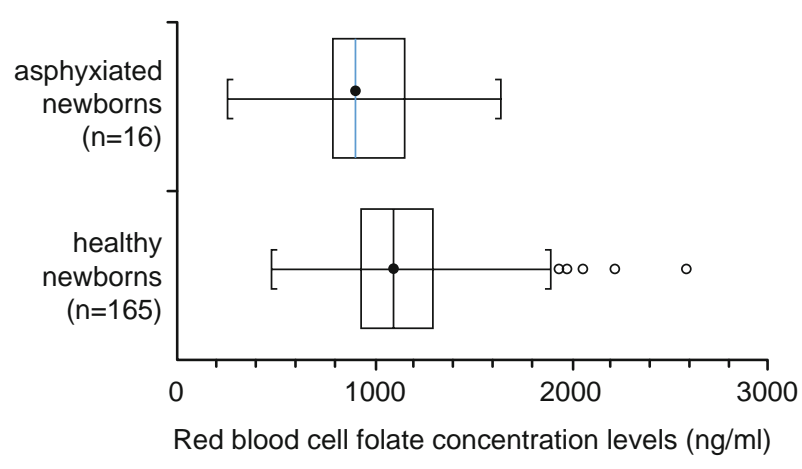

Fig. 1. Red blood cell folate concentration levels in asphyxiated and healthy newborns on the first day of life $(p=0.023)$.

The gender of study group $(n=181)$

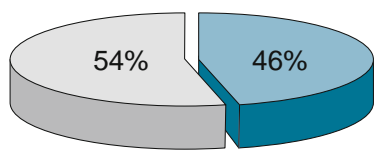

Males ( $\mathrm{n}=84$; median of RBC folate $1167 \mathrm{ng} / \mathrm{ml}$ )

Females ( $\mathrm{n}=97$; median of RBC folate $1127 \mathrm{ng} / \mathrm{ml}$ ) $\mathrm{p}=0.67$

Fig. 2. The findings of red blood cell (RBC) folate concentration levels due to gender in our study group $(p=0.67)$.

phyxia should be present by profound metabolic or mixed acidemia $(\mathrm{pH}<7.00)$ in umbilical cord arterial blood sample; persistence of Apgar score of 0-3 for $>5 \mathrm{~min}$; neurologic manifestations in the immediate neonatal period includes seizures, hypotonia, coma, or hypoxic-ischemic encephalopathy; evidence of multiorgan system dysfunction in the immediate neonatal period (2). Asphyxia is one of the risk factors which have been identified in cerebral palsy (18). Maternal infections and prematurity are also important risk factors for birth asphyxia mortality. Premature infants are at higher risk of birth asphyxia mortality compared to term infants (19). In our study we identified $63 \%$ of asphyxiated newborns as being born prematurely. Other factors such as abnormal fetal heart rate, prior Caesarean delivery, maternal age of 35 years or older were detected as independent risk factors of severe neonatal acidosis, which can lead to perinatal asphyxia (20).

The red blood cell folate is the primary indicator to determine folate adequacy. Because folate is taken up only by the developing erythrocyte in the bone marrow and not by the circulating mature erythrocyte during its 120-day lifespan, erythrocyte folate concentration is an indicator of long-term status (21). The normal range of $\mathrm{RBC}$ folate values vary due to the different analytical methods used for assessing RBC folate concentrations (22). The best indicator of long-term folate levels in the body is the RBC folate concentration level. Differences were observed in breastfed infants independent of maternal folate status which suggested that concentration of folate decreases from birth up to 24 months (23). The significant influence of other factors on

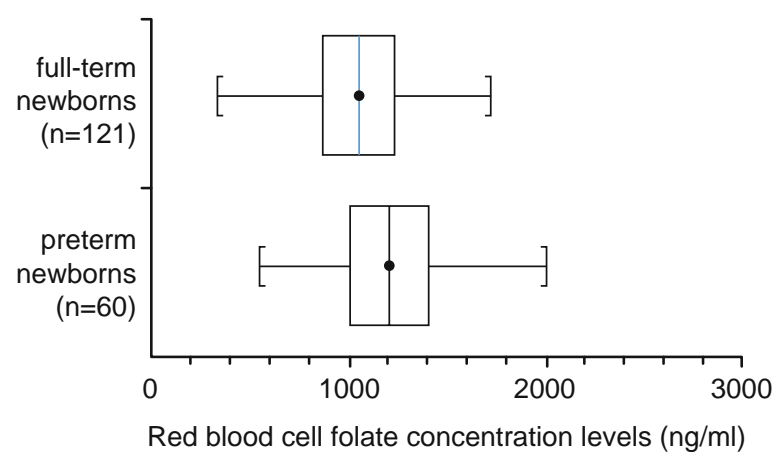

Fig. 3. Red blood cell folate concentration levels in preterm newborns in comparison with full-term newborns $(p=0.01)$ on the first day of life.

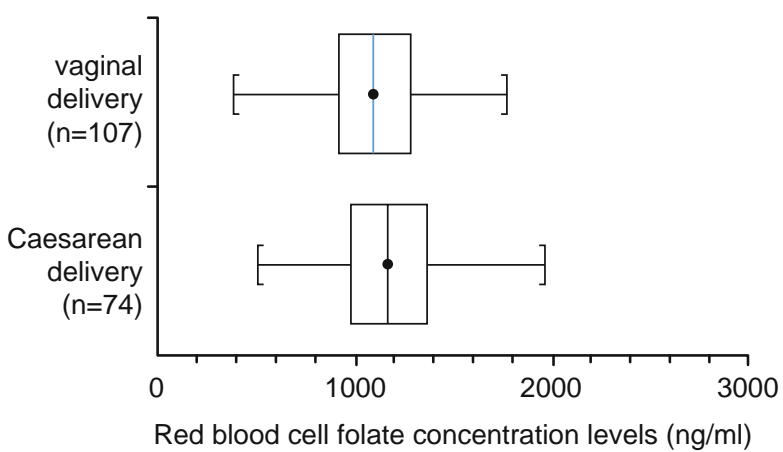

Fig. 4. Impact of different mode of delivery on red blood cell folate concentration levels in newborns from umbilical cord blood samples $(p=0.02)$.

RBC folate concentration levels which had been noted were e.g. climate, race (24) or smoking habits (25). The genetic polymorphisms of the MTHFR (methylenetetrahydrofolate reductase) can be also associated with some disorders such as major depressive disorders (26). Different climate and nutritional habits can have influence on prevalence of congenital anomalies as e.g. cleft palate in some regions of European countries $(27,28)$. It can alter the RBC folate concentration levels in organism. Decreased serum folate levels are correlated with the occurrence of neonatal asphyxia (29). The results of our prospective study were similar to those of Mi et al (2008). RBC folate concentration levels were not impacted by gender in our study. Laboratory findings associated with perinatal asphyxia pointed out the changes in blood count parameters such as erythrocyte count and hemoglobin and hematocrit values (9). On the other hand the chronic long-term intermittent hypoxia leads to an increase in haematocrit and whole blood viscosity (30).

One of further determinants of folate levels can be the gestational age. Some authors suggest the association between low maternal serum folate and risk of preterm birth (31). Joythi et al did not find differences due to gestational age (32). The placental transfer of vitamins can vary according to gestational age and body reserves. We confirmed higher RBC folate concentration levels in preterm newborns in comparison with the group of full-term 
417-421

newborns, while the difference was statistically significant. We believe that an interaction between other substances in metabolism pathways has taken place, which might have led to raised RBC folate concentration levels. One of probable factors could lie in good maternal folate status during pregnancy. The maternal status of group B vitamins during pregnancy can be lower (33) and the impact on newborns is uncertain. Additional studies are required to elucidate the subsequent effects.

On the other hand the clearly positive effects of folic acid in prenatal and neonatal period were published in many studies. Nevertheless, excessive doses of folic acid could present the risk of accumulation and possible adverse effects (34).

Red blood cell folate concentration tended to change based on many factors. Mode of delivery, e.g. cesarean delivery could avert intrapartum fetal trauma and asphyxia and allow timed delivery to assure readiness of neonatal intensive care resources. Asphyxia can lead to changes in blood count parameters (9) and probably in RBC folate concentration levels as confirmed by Mi et al (29) as well as by the results of our study. A lot of retrospective and observational studies do not support routine cesarean delivery for all early preterm infants. Cesarean delivery may offer survival advantage to the periviable growth-restricted infant, regardless of fetal presentation and appears to offer survival benefit to the malpresenting fetus (35). The mode of delivery can influence the RBC folate concentration levels. We believe there is an impact resulting from certain mechanical injuries, but it is necessary to know the level of bilirubin. This could be due to the lack of research in our study, as the level of bilirubin was not studied in umbilical cord blood samples of our newborns. On the other hand, it is the confirmation of the presence of physiological changes during vaginal delivery that suggests that RBC folate concentration levels are very similar to the findings in a group of healthy full-term newborns in our country (36). During asphyxia, the RBC folate concentration levels decreased in spite of physiological blood count parameters (unpublished data).

\section{Conclusion}

Folates are important parts of some metabolic processes in the human body in the first months of life. The analysis of its concentration in erythrocytes is an accurate indicator of the body's saturation with folic acid. RBC folate concentration is influenced by several factors on the side of both the mother and the newborn and/or other associated complications. In our prospective study we confirmed a significant decrease in RBC folate concentration levels in umbilical cord blood samples in asphyxiated newborns on their first day of life. Most of these asphyxiated newborns were born premature. With the increase in gestational age the $\mathrm{RBC}$ folate concentration levels decreased. Another factor which could have had an impact on RBC folate concentration levels detected by us was the mode of delivery. The decreased RBC folate concentration levels are not associated with gender. It can be due to other factors such as the size of selected group or division into specific sub-groups. This issue needs to be studied in greater depth.

\section{References}

1. Kerac M, Postels DG, Mallewa M, Alusine Jalloh A, Voskuijl WP, Groce N, Gladstone M, Molyneux E. The interaction of malnutrition and neurologic disability in Africa. Semin Pediatr Neurol 2014; 21 (1): 42-49.

2. Gomella TL et al. Neonatology: management, procedures, on-call problems, diseases and drugs. 6th ed. USA: McGraw-Hill Companies; 2009. ISBN 978-0-07-154431-3.

3. Herrera-Marschitz M, Neira-Pena T, Rojas-Mancilla E, EspinaMarchant P, Esmar D, Perez R, Muńoz V, Gutierrez-Hernandez M, Rivera B, Simola N, Bustamante D, Morales P, Gebicke-Haerter P. Perinatal asphyxia: CNS development and deficits with delayed onset. Front Neurosci 2014; 8 (47): 1-11.

4. Mohamed AM, Aly H. Impact of race on male predisposition to birth asphyxia. J Perinatol. 2014. doi: 10.1038/jp.2014.27.

5. Lencesova L, Krizanova O. IP(3) receptors, stress and apoptosis. Gen Physiol Biophys 2012; 31 (2): 119-130.

6. Simović AM, Kosutić JLj, Prijić SM, Knezević JB, Vujić AJ, Stojanović ND. The role of biochemical markers as early indicators of cardiac damage and prognostic parameters of perinatal asphyxia. Vojnosanit Preg 2014; 71 (2): 149-155.

7. Brucknerova I, Benedekova M, Pechan I, Holoman K, Bieliková E, Kostrová A, Ujházy E, Dubovicky M, Mach M. Delivery as a "physiological stress" and its influence on some parameters of oxidative stress. Neuro Endocrinol Lett 2006; 27 Suppl 2: 65-68.

8. Bjelakovic L, Kocic G, Stojanovic I, Jevtovic-Stoimenov T, Najman S, Sokolovic D, Stojanovic S, Bjelakovic G. Folic acid effect on arginase activity in human colostrum and mature milk. Pteridines 2012; 23: 33-38.

9. Brucknerova I, Ujházy E, Dubovicky M, Mach M. Early assessment of the severity of asphyxia in term newborns using parameters of blood count. Interdiscip Toxicol 2008; 1 (3-4): 211-213.

10. Beaudin AE, Stover PJ. Folate-mediated one-carbon metabolism and neural tube defects: balancing genome synthesis and gene expression. Birth Defects Research (Part C) 2007; 81 (3): 183-203.

11. Hoffbrand AV, Weir DG. Historical review. The history of folic acid. Br J Haemat 2001; 113: 579-589.

12. Capra L, Tezza G, Mazzei F, Boner AL. The origins of health and disease: the influence of maternal diseases and lifestyle during gestation. Ital J Pediatr 2013; 39: 7.

13. Raza MZ, Sheikh A, Ahmed SS, Ali S, ANaqvi SMA. Risk factors associated with birth defects at a tertiary care center in Pakistan. Ital J Pediatr 2012, 38: 68.

14. Guardamagna O, Abello F, Cagliero P, Lughetti L. Impact of nutrition since early life on cardiovascular prevention. Ital J Pediatr 2012; $38: 73$.

15. Madaric A, Kadrabova J, Krajcovicova-Kudlackova M, Valachovicova M, Spustova V, Mislanova C, Kajaba I, Blazicek P. The effect of bioactive complex of quercetin, selenium, catechins and curcumin on cardiovascular risk markers in healthy population after a two month consumption. Bratisl Med J 2013; 114 (2): 84-87.

16. Lietava J, Vohnout BB, Dukat A, Fodor GJ. Homocysteine Slovakia study: study design and occurrence of hyperhomocysteinaemia and other risk factors. Bratisl Med J 2012; 113 (2): 80-86.

17. Zemlin AE, Essack Y, Rensburg M, Keller T, Krinkmann T. Stability of red blood cell folate in whole blood and haemolysate. Clin Lab 2010; 56 (9-10): 391-396. 
18. McIntyre S, Taitz D, Keogh J, Goldsmith S, Badawi N, Blair E. A systematic review of risk factors for cerebral palsy in children born at term in developed countries. Dev Med Child Neurol 2013; 55 (6): 499-508.

19. Lee AC, Mullany LC, Tielsch JM, Katz J, Khatry SK, LeClerq SC, Adhikari RK, Shrestha SR, Darmstadt GL. Risk Factors for Neonatal Mortality Due to Birth Asphyxia in Southern Nepal: A Prospective, Community-Based Cohort Study. Pediatrics 2008; 121 (5): 381-390.

20. Maisonneuve E1, Audibert F, Guilbaud L, Lathelize J, Jousse M, Pierre F, Fraser W, Carbonne B. Risk factors for severe neonatal acidosis. Obstet Gynecol 2011, 118 (4): 818-823.

21. Institute of Medicine, Food and Nutrition Board. Dietary reference intakes for thiamin, riboflavin, niacin, vitamin B6, folate, vitamin B12, pantothenic acid, biotin, and choline / a report of the Standing Committee on the Scientific Evaluation of Dietary Reference Intakes and its Panel on Folate, Other B Vitamnis, and Choline and Subcommittee on Upper Reference Levels of Nutrients, National Academy Press, Washington, DC; 1998. ISBN 0309065542.

22. Jackson A. Folate and disease prevention. London: TSO; 2006. Available at: http://www.sacn.gov.uk/pdfs/folate_and_disease_prevention_report.pdf

23. Hay G, Johnston C, Whitelaw A, Trygg K, Refsum H. Folate and cobalamin status in relation to breastfeeding and weaning in healthy infants. Am J Clin Nutr 2008; 88 (1): 105-114.

24. Zhu L, Ling H. National Neural Tube Defects Prevention Program in China. Food Nutr Bull 2008; 29 (2): 196-204.

25. Bjørke-Monsen AL, Vollset SE, Refsum H, Markestad T, Ueland PM. Hematological parameters and cobalamin status in infants born to smoking mothers. Biol Neonate 2004; 85 (4): 249-255.

26. Evinova A, Babusikova E, Straka S, Ondrejka I, Lehotsky J. Analysis of genetic polymorphisms of brain-derived neurotrophic factor and methylenetetrahydrofolate reductase in depressed patients in a Slovak (Caucasian) population. Gen Physiol Biophys 2012; 31 (4): 415-422.
27. Fedeles J, Ziak P, Krizko M, Payer J, Bohac M, Palencar D, Hulin I, Fedeles J. Prevalence of cleft lip and palate in western Slovakia in the years 2001-2007. Bratisl Med J 2012; 113 (2): 117-119.

28. Urbanova W, Kotova M, Vankova Z. The incidence of cleft lip and palate in the Czech Republic in 1994-2008. Bratisl Med J 2013; 114 (8): 474-479.

29. Mi WY, Liu W, Liu TC, Zhou X, Ma CM, Li ZY, Wang WH, Lin YP. Serum levels of homocysteine and folate in neonates with asphyxia. Zhongguo Dang Dal Er Ke Za Zhi. 2008; 10 (2): 130-132.

30. Yelmen N, Ozdemir S, Guner I, Toplan S, Sahin G, Yaman OM, Sipahi S. The effects of chronic long-term intermittent hypobaric hypoxia on blood rheology parameters. Gen Physiol Biophys 2011; 30: 389-395.

31. Bodnar LM, Himes KP, Venkataramanan R, Chen JY, Evans RW, Meyer JL, Simhan HN. Maternal serum folate species in early pregnancy and risk of preterm birth. Am J Clin Nutr 2010; 92 (4): 864-871.

32. Jyothi S, Misra I, Morris G, Benton A, Griffin D, Allen S. Red cell folate and plasma homocysteine in preterm infants. Neonatology. 2007; 92: 264-268.

33. Halicioglu O, Sutcuoglu S, Koc F, Ozturk C, Albudak E, Colak A, Sahin E, Asik Akman S. Vitamin B12 and folate statuses are associated with diet in pregnant women, but not with anthropometric measurements in term newborns. J Matern Fetal Neonatal Med 2012; 25 (9): 1618-1621.

34. Zikavska T, Brucknerova I. Position of folic acid in fortification of nutrition in neonatal period. Potravinarstvo 2013; 7 (1): 202-206.

35. Mercer BM. Mode of delivery for periviable birth. Semin Perinatol 2013; 37 (6): 417-421.

36. Zikavska T, Brucknerova I, Vasilenkova A, Gallikova M. Red blood cell folate status on the first day of life in newborn and its specifics. Czech-Slovak Pediatrics 2013; 68 (S1): 74. 